\title{
Optimization of Generalized Predictive Control (GPC) Tuning Parameters By Response Surface Methodology (RSM)
}

\author{
Adnan Aldemir, Hale Hapoğlu and Mustafa Alpbaz \\ Ankara University, Faculty of Engineering, Department of Chemical Engineering, \\ 06100, Ankara, Turkey \\ aldemir@eng.ankara.edu.tr
}

\begin{abstract}
Response Surface Methodology(RSM) was successfully applied to a process simulator for optimization of Generalized Predictive Control(GPC) tuning parameters. Wireless experimental input/output data obtained from process simulator. GPC algorithm which is written in MATLAB is utilized to wireless temperature control experiments achieved by using MATLAB/Simulink program.The efficiency of the GPC is observed by calculating the integral of the square of the error (ISE) and the integral of the absolute value of the error (IAE) from experimental results which was optimized by the application of RSM. The three independent variables, which had been found the most effective variables on the GPC by screening experiments, were determined as $N_{U}, N_{2}$ and $\lambda$ as minimum prediction horizon, maximum prediction horizon and control weighting, respectively. The quadratic models were developed through RSM in terms of related independent variables to describe the ISE and IAE as the two response. Based on statistic analysis, optimum GPC tuning parameters of $N_{U}\left(X_{1}\right), N_{2}\left(X_{2}\right)$ and $\lambda\left(X_{3}\right)$ for minimize the ISE were determined to be 1.7922, 1.9453 and 0.0642 and for minimize the IAE were determined to be 1.8880, 1.9752 and 0.0612, respectively. Calculated optimum points of GPC tuning parameters are close to based on ISE and IAE results. The data evaluated from the quadratic model were good agreement with those measured experimentally. The wireless temperature control is successfully applied to the process simulator and wireless control technique is proposed for various application areas.
\end{abstract}

Keywords: GPC, RSM, ISE, IAE, wireless process control, MATLAB/Simulink, optimization

\section{Introduction}

Generalized Predictive Control (GPC) is selected since it is considered one of the most popular Model Predictive Control (MPC) algorithms in industry. GPC with integral action is derived based on the minimization of a modified predictive performance criterion. The GPC algorithm is easy to implement and robust with respect to modeling errors, uncertainties, and sensor noise. The GPC algorithm has been successfully used in many applications, e.g. non-minimum phase systems, open-loop unstable systems, and systems with variable or unknown dead time. In addition, the GPC algorithm can not only improve the convergence performance, but also reduce the computational complexity [1-4]. GPC has been successfully applied in the various processes such as distillation columns [5], polymerization reactors [6], exothermic chemical reactions [7], $\mathrm{pH}$ neutralization of a tubular flow reactors [8], biochemical processes [9-10], power plant [11] and flotation plant [12]. Experimental studies demonstrate, GPC is superior to accepted techniques such as Generalized Minimum Variance (GMV) or pole placement. The popularity of GPC due to its relatively simple time-domain formulation and good performance on the process. The basic principle of GPC is to predict the process output over a long range time horizon using a mathematical model. 
The GPC internal model and the GPC tuning parameters are two key components within the structure of the controller can be made adaptive. Practically GPC applied with four tuning parameters. There have been a few papers that have suggested how to tune the four parameters. These parameters are following abbreviations: $\mathrm{Nu}$ is the control horizon, $\mathrm{N}_{1}$ and $\mathrm{N}_{2}$ are the minimum and maximum prediction horizons, respectively and $\lambda$ is the control weighting. McIntosh et al. [13] provide three tuning strategies for GPC. In each strategy, all parameters except one are fixed, while the remaining parameter was tuned. The first tuning strategy varies $\mathrm{N}_{2}$, the prediction horizon, to match the desired speed of response, i.e. the ability to force the output to respond to step changes in set point. The control horizon is set to one, making this method relevant only to industrial-type plants. The second strategy tunes $\lambda$. The tuning starts with $\lambda=0$, which results in a deadbeat controller and is then progressively detuned by increasing $\lambda$. Again, this approach is appropriate for the industrial setting. The third approach is detuned model following. This is accomplished by filtering the output sequence. This in essence allows the user to place the poles at an arbitrary, yet predetermined position [14].

MATLAB, developed by the MathWorks Inc., has been a powerful software for mathematical computations and visualisations. Simulink is a part of MATLAB for modelling, simulation, and analysis of dynamical systems in a flowsheeting environment. It supports linear and nonlinear systems, modelled in continuous time, sampled time or a hybrid of the two. Bequette [15] illustrated that the interactive MATLAB/Simulink tool enhances the ability to learn new model-based techniques and provide an inside depth of the dynamic nature and control of chemical processes. For modelling, Simulink provides a graphical user interface (GUI) for building models as block diagrams, using click-and-drag mouse operations. With this interface, drawing the models just as we would with pencil and paper. Simulink includes a comprehensive block library of sinks, sources, linear and nonlinear components, and connectors. Users can also customize and create own block models using the S-Function format. This approach provides insight into how a model is organized and how its parts interact. After defining a model, user can simulate it, using a choice of integration methods, either from the MATLAB/Simulink menus or by using MATLAB's m-files. The menus are particularly convenient for interactive work, while the $\mathrm{m}$-file approach is very useful for running a batch of simulations. Using scopes and other display blocks, user can see the simulation results while the simulation is running. In addition, user can change parameters and immediately see what happens, for "what if" exploration. The simulation results can be put in the MATLAB m-files for post processing and visualization. MATLAB and Simulink are integrated user can simulate, analyse, and revise your models in either environment at any point [16]. Therefore, modelling and control of stagewise processes is now common using MATLAB/Simulink with its versatile environment to get rapid and accurate simulation for models of varying degree of complexity.

Wireless process control (WPC) have many industrial applications such as monitoring, detection, and automation. The main benefit of wireless WPC is the avoidance or minimization of cabling costs, smaller engineering devices, required low energy, low power consumption, flexibility, scalability and assembly times, the ease of system extensions and changes and the possibility to apply sensors to mobile devices and device parts. In many applications, wireless control is more reliable than wired ones, because wireless connections cannot be broken mechanically as happens to wired ones. In addition, the wirings and connections can suffer from aging because of the hot process environments. The energy required for a wireless communication can be supplied in many ways. Using batteries is perhaps the easiest approach, but the inherent limited operation time and limited functional features can reduce the usefullness of battery-powered wireless applications. 


\section{Generalized Predictive Control (GPC) Technique}

Experimental design which is used in optimization method, includes some specific ranges of the variables which are changed between the highest and the lowest level. For every set of ranges of the variables, optimization provides a specific set point. When the set of ranges in the experimental design matrix is exceeded, optimization procedure choses a new set of ranges which is included in the data bank, and optimization stage calculates the new optimal set point. To establish the GPC algorithm it is supposed that a model of the linearized plant is expressed in terms of the following ARIMAX form Eq.(1)

$$
A y(t)=B u(t-1)+\frac{C}{\Delta} e(t)
$$

The function of the $\Delta$ operator $\left(\Delta=1-\mathrm{z}^{-1}\right)$ is to guarantee integral action in the controller which eliminate offset, i.e. a steady-state output disturbance. The polynomial $\mathrm{C}\left(\mathrm{z}^{-1}\right)$ can then always be accepted as a stable polynomial since only the spectral properties of the signal $(\mathrm{C} / \Delta) \mathrm{e}(\mathrm{t})$ affect the predictions of future values of $\mathrm{y}_{\mathrm{t}}$. The cost function to be minimized is Eq (2)

$$
\mathrm{J}\left(\mathrm{N}_{1}, \mathrm{~N}_{2}, \mathrm{~N}_{\mathrm{U}}, \lambda\right)=\sum_{\mathrm{J}=\mathrm{N}_{1}}^{\mathrm{N}_{2}} \varepsilon^{2}(t+j)+\lambda \sum_{j=1}^{\mathrm{N}_{\mathrm{U}}} \Delta U^{2}(t+j-1)
$$

where, $\mathrm{N}_{1}$ is termed the minimum costing horizon, $\mathrm{N}_{2}$ the maximum costing horizon, and $\mathrm{N}_{\mathrm{u}}$ the control costing horizon. The signal $\mathrm{r}_{t}$ is the reference signal which is chosen for the system output to track. The positive constant $\lambda$ (control weighting) adds weight to the relative importance of the control and tracking errors. The expectation $\mathrm{E}$ is used in Eq. (2) to denote that the control values selected are estimated from data obtained up to and including time $t$ and that a stochastic disturbance model has been assumed.

The optimization scheme is implemented for $\mathrm{N}_{2}-\mathrm{N}_{1}+1$ successive future output values, taking $\mathrm{N}_{\mathrm{u}}$ future incremental control actions into account. The assumption is that this algorithm will be successful provided that the true delay is contained in the interval between $\mathrm{N}_{1}$ and $\mathrm{N}_{2}$. The GPC tuning parameters may be set according to the following guidelines Clarke [2];

(a) The minimum costing horizon $N_{l}$, If the process dead-time $\mathrm{k} \Delta \mathrm{t}$ is known precisely, then $\mathrm{N}_{1}$ should be set at $\mathrm{k}_{1}$ since making $\mathrm{N}_{1}$ smaller than $\mathrm{k}$ would mean carrying out unnecessary computations. If $\mathrm{k} \Delta \mathrm{t}$ is not known or is a variable, then $\mathrm{N}_{1}$ can be set at 1 without any loss in stability.

(b) The maximum costing horizon $\mathrm{N}_{2}$, If the plant is non minimum-phase and initially produces a negative response, $\mathrm{N}_{2}$ should be selected such that later positive output samples are included in the cost. In practice, a large value of $\mathrm{N}_{2}$ is generally employed, corresponding more closely to the rise-time of the plant.

(c) The control costing horizon $N_{U}$, For a simple plant letting $\mathrm{N}_{\mathrm{U}}=1$ usually provides acceptable control. Increasing $\mathrm{N}_{\mathrm{U}}$ causes the controller to become more active up to a point where any further increment makes very little difference.

(d) The control weighting $\lambda$, Normal practice is to put $\lambda=0$, although sometimes setting $\lambda=\delta$ (where $\delta$ is small) is necessary to obtain acceptable control for systems which show oscillatory behaviour.

The efficiency of the GPC algorithm was observed by calculating the performance criteria such as ISE and IAE values from the experimental results given in Eq (3) and Eq (4). 


$$
\begin{aligned}
& \text { IS E }=\sum_{0}^{t}[y(t)-r(t)]^{2} \\
& \text { I A E }=\sum_{0}^{t}|y(t)-r(t)|
\end{aligned}
$$

There have been few studies dealing with the determined GPC tuning parameters by trial and error method on various processes in which only the effect of one parameter has been investigated at a time, being incapable of predicting the interaction between independent variables. But there is no report on the application of RSM on GPC tuning parameters in the literature. In the present study, experimental input/output data is obtained from process control simulator. Wireless temperature control is achieved by utilizing GPC algorithm which is written in MATLAB/Simulink program is used for control experiments. The wireless experimental GPC results with different $\lambda$ values are compared by observing the temperature profiles and calculated ISE, IAE values compared for determining efficiency of GPC.

\section{Experimental System Description and Methods}

The process control simulator consists of two main units, an instrument console and a framework carrying the process equipment which is shown in Figure 1. The instrument console contains the electronic flow, level, temperature controllers and electrical switchgear. It is connected to the process equipment by several cable assemblies. The process equipment consists of a water tank, water circulating pump, electrical water heater, two vessels, two electrically positioned control valves and a heat exchanger. In process control simulator, twelve manual valves are available for different process experiment loops. In the simulator, temperature measurement and control can be made at four different points which are first tank, heater output, second tank input and output. The system developed for transferring data between the computer and the panel. Data transfer is achieved wirelessly by using the two antenna are found in the laboratory connected to the computer and outside connected to the process simulator. Control valves outputs are connected to the modules, the necessary calibrations are made. The water is pumped via the electrical heater into the reactor up to a certain level. The water then flows back to the sump tank via the cooler. Heat is fed to the water by the heater and residual heat removed by the cooler so as to return the sump tank water temperature to a suitable base level. Heater which is connected on-line to the computer is used as a manipulated variable [17].

The water is pumped via the electrical heater into vessels V1 and V2 in series, thus simulating a reactor vessel with considerable thermal mass. The water then flows back to the sump tank via the cooler. Heat is input to the water by the heater and residual heat removed by the cooler so as to return the sump tank water temperature to a suitable base level. Four thermocouples (T1 - T4) monitor the temperature at different points around the circuit. A selector switch is provided so that any one of the temperatures T2, T3 or T4 can be input to the temperature controller as the process variable. T2 is located at the outlet from the heater and thus provides minimum process response time while T3 and T4 are positioned after V1 and V2 respectively and thus allow the study of systems with greater response times. The selected thermocouple signal is fed into the Eurotherm 3 term temperature controller, the output from which controls the power fed to the heater via two thyristor unit controlling 2 legs of a balanced 3 phase star connected load. The base water temperature is measured by 'T1 at the outlet from the pump. The controller input (process variable), controller output signal and all process temperatures can be recorded on the SCADA package. By varying the temperature difference between the control set point and base temperature, the effect of varying system load can be demonstrated. 


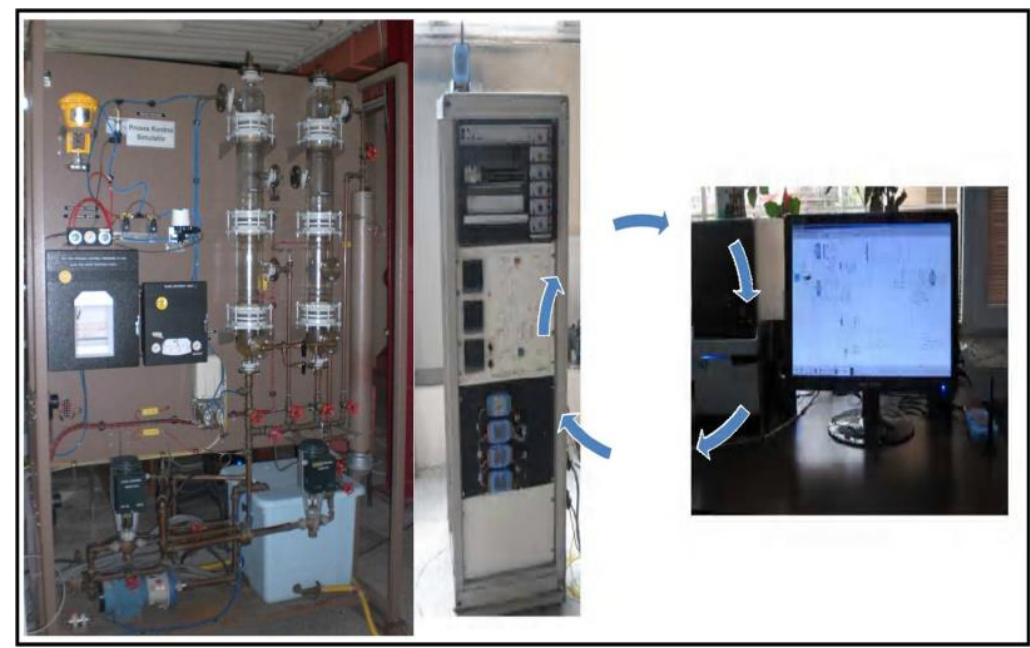

\section{Figure 1. Experimental System: Process Simulator, Control Panel and Computer On-line Connected to Simulator with Wireless Technology}

Wireless temperature control experiments were carried out on process simulator during the $1 \mathrm{~h}$ time period. First, the steady-state experiments were performed. The fluid flow is obtained by running the pump when the liquid level control valve is opened at a certain level. The cooling water is opened after liquid level is fixed. The heater output temperature is expected to become at steady-state while \% heating capacity is on. The temperature is monitored when system has become at steady-state condition. To obtain the desired temperature in the face of set point change, the MATLAB/Simulink program for GPC block shown in Figure 2 is used. First 10 min the heater operated $\% 10$ heating capacity for the temperature is expected to become at steady-state. The temperature is monitored when system has become at steady-state GPC algoritm $\mathrm{N}_{\mathrm{U}}, \mathrm{N}_{2}$ and $\lambda$ tuning parameters of GPC were chosen as the independent operating variables while ISE and IAE were the responses in the light of screening experiments and the literature research. After experiments of RSM, ISE and IAE values were calculated and data performed the Design Expert 7.0.0 program for statistic analysis. Range and level of the independent variables used in this experimental study $\mathrm{N}_{1}, \mathrm{~N}_{2}$ and $\lambda$ were given in Table 1 . Different step disturbances were given to input variables and on-line GPC algorithm program was executed by using optimal operating conditions of the process simulator for wireless temperature control.

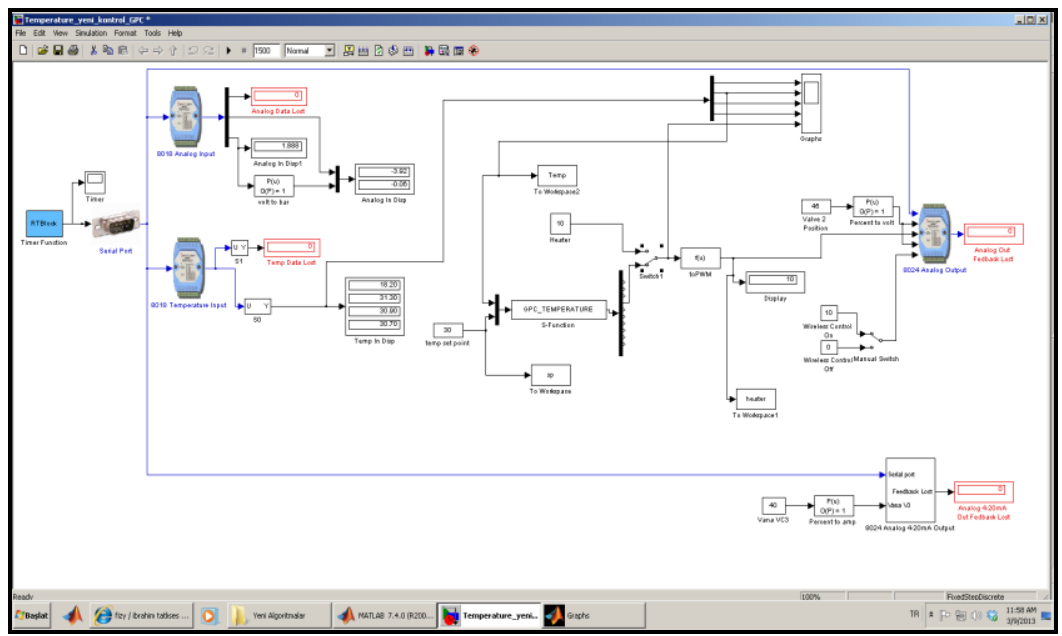

Figure 2. MATLAB/Simulink Program for Wireless Temperature Control 


\subsection{Experimental Design and Analysis}

Response surface methodology (RSM) based on the Central Composite Design (CCD) has been widely employed to investigate the effect of variables and to seek the optimum conditions for a multivariable system. To explore the effect of variables on the response in the region of investigation, a CCD with three variables at three levels was performed. $\mathrm{N}_{1}$, $\mathrm{N}_{2}$ and $\lambda$ tuning parameters were considered the independent variables according to GPC technique. ISE and IAE values were taken as the responses according to literature research. The CCD was applied using Design-Expert 7.0.0 program (trial version). The total number of experiments with three variables were $20\left(=2^{k}+2 k+6\right)$, where $k$ is the number of independent variables. Fourteen experiments were augmented with six replications at the center points (zero level) to determine the experimental error and the reproducibility of the data. The independent variables are coded to the $(-1,+1)$ interval where the low and high levels are coded as -1 and +1 , respectively. The axial points are located at distance of $\alpha$ from center and make the design rotatable. In this study, $\alpha$ value was fixed at 1.682. The range and the levels of the variables under investigation in this study are given in Table 1. In the regression equation, the test variables were coded according to the Equation (5);

Table 1. Experimental Range and Levels of Variables

\begin{tabular}{|c|ccccc|}
\hline \multirow{2}{*}{ Variables } & \multicolumn{5}{|c|}{ Range and level } \\
\cline { 2 - 6 } & $-\alpha$ & -1 & 0 & +1 & $+\alpha$ \\
\hline $\mathrm{N}_{U}$ & 0.32 & 1.00 & 2.00 & 3.00 & 3.68 \\
\hline $\mathrm{N}_{2}$ & 0.32 & 1.00 & 2.00 & 3.00 & 3.68 \\
\cline { 1 - 4 } & 0.01 & 0.03 & 0.06 & 0.09 & 0.11 \\
\hline
\end{tabular}

$x_{i}=\frac{X_{i}-X_{0}}{\Delta X}$

where, $x_{i}$ is the dimensionless coded value of the independent variable, $X_{i}$ is the independent variable real value, $X_{0}$ is the independent variable real value on the center point and $\Delta X$ is the step change value.

In the optimization process the response can be related to chosen variables by linear or quadratic models. A quadratic model is given as follows:

$$
y=\beta_{0}+\sum_{i=1}^{3} \beta_{i i} x_{i}+\sum_{i=1}^{3} \beta_{i i} x_{i}^{2}+\sum_{i=1}^{3} \sum_{j=i+1}^{3} \beta_{i j} x_{i} x_{j}+e
$$

where $\mathrm{y}$ is the response, $\beta_{0}$ the constant coefficient, $x_{i}(i=1-3)$ are none coded variables, $\beta_{i} \mathrm{~s}$ are the linear, and $\beta_{i i} \mathrm{~s}(i$ and $j=1-3)$ are second order interaction coefficients. The residuals for each experiment were computed as $e_{i}=y_{i}-\hat{y}_{i}, i=1,2, \ldots, \mathrm{n}$, where $e_{i}, y_{i}$ and $\hat{y}_{i}$ are residual of $i$ th experiment, observed response and predicted response, respectively.

Data were processed for Equation (6) using Design Expert 7.0.0 program including ANOVA to obtain the interaction between the process variables and response. The quality of the fit of polynomial model was expressed by the coefficient of determination $\mathrm{R}^{2}$ and 
statical significance was checked by the $F$-test using the same program. The second ordermodel determined from Equation (6) is adequate for the optimal points. A general mathematical solution can be obtained by Equation (7) for the location of the stationary point [38]. Writing the second-order model in matrix notation, it was:

$$
y=\beta_{0}+x^{I} b+x^{I} B x_{s}
$$

where

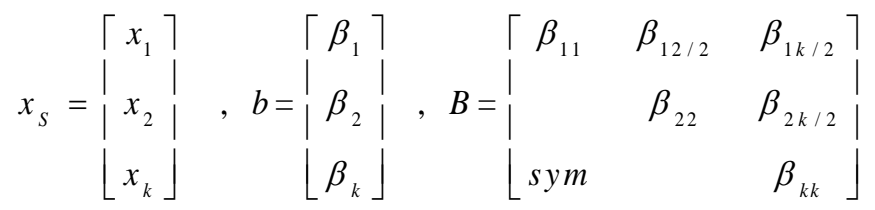

That is, $\boldsymbol{b}$ is a $(k x 1)$ vector of the first order regression coefficient and $\boldsymbol{B}$ is a $(k x k)$ symmetric matrix whose main diagonal elements are the pure quadratic coefficients ( $\beta i i)$ and whose off-diagonal elements are one half the mixed quadratic coefficients $(\beta i j, i \neq j)$. The stationary points $(x s)$ are the solution of Equation (8):

$$
x_{S}=-\frac{1}{2} B^{-1} b
$$

\section{Results and Discussion}

Wireless temperature control experiments were carried out on process simulator during the $1 \mathrm{~h}$ time period. First $10 \mathrm{~min}$ the heater operated $\% 10$ heating capacity for the temperature is expected to become at steady-state. For determine to $\mathrm{N}_{1}$, a step change is given from heater via a computer and system's response to this effect which is the tank outlet temperature has been observed. The reaction curve is prepared from this dynamic analysis and the dead time, static gain and time constant parameters are determined $0.85,0.75,2.167$, respectively. $\mathrm{N}_{\mathrm{U}}, \mathrm{N}_{2}$ and $\lambda$ tuning parameters of GPC were chosen as the independent operating variables while ISE and IAE were the responses in the light of screening experiments and the literature research. The effects of three parameters, $\mathrm{N}_{\mathrm{U}}, \mathrm{N}_{2}$ and $\lambda$ were studied with the help of Design-Expert 7.0.0 program and the subsequent statistical analysis was performed by RSM. A statistical approach with a CCD was used for determining the interaction between these factors. The ranges of $\mathrm{N}_{\mathrm{U}}, \mathrm{N}_{2}$ and $\lambda$ parameters for CCD operating conditions were determined with pre-experiments. The region of exploration to locate the optimum operating conditions was decided 1-3, 1-3 and 0.01-0.09 as $\mathrm{N}_{\mathrm{U}}, \mathrm{N}_{2}$ and $\lambda$, respectively. The CCD was conducted with 20 experiments, including 8 star points, 6 axial points corresponding to the alpha value and 6 replicates at the center points. The tuning parameters at the center point were $\mathrm{N}_{\mathrm{U}} 2.0, \mathrm{~N}_{2} 2.0$ and $\lambda 0.06$, which have been used for tuning of GPC. 
Table 2. Experimental Design of CCD Runs with Calculated Responses

\begin{tabular}{|cllllr|}
\hline Run & \multicolumn{1}{c}{$\mathbf{N}_{\mathbf{U}}$} & \multicolumn{1}{c}{$\mathbf{N}_{\mathbf{2}}$} & \multicolumn{1}{c}{$\boldsymbol{\lambda}$} & \multicolumn{1}{c}{ ISE } & \multicolumn{1}{c|}{ IAE } \\
\hline & $\left(X_{1}\right)$ & $\left(X_{2}\right)$ & $\left(X_{3}\right)$ & $\left(R_{1}\right)$ & $\left(R_{2}\right)$ \\
\hline $\mathbf{1}$ & $2.00(0)$ & $2.00(0)$ & $0.06(0)$ & 232605 & 9521 \\
$\mathbf{2}$ & $2.00(0)$ & $2.00(0)$ & $0.06(0)$ & 232135 & 9554 \\
$\mathbf{3}$ & $2.00(0)$ & $3.68(+\alpha)$ & $0.06(0)$ & 267275 & 11159 \\
$\mathbf{4}$ & $1.00(-1)$ & $1.00(-1)$ & $0.03(-1)$ & 266695 & 11129 \\
$\mathbf{5}$ & $1.00(-1)$ & $3.00(+1)$ & $0.09(+1)$ & 252190 & 9825 \\
$\mathbf{6}$ & $0.32(-\alpha)$ & $2.00(0)$ & $0.06(0)$ & 246435 & 10718 \\
$\mathbf{7}$ & $3.00(+1)$ & $1.00(-1)$ & $0.03(-1)$ & 267655 & 11098 \\
$\mathbf{8}$ & $2.00(0)$ & $2.00(0)$ & $0.06(0)$ & 231570 & 9585 \\
$\mathbf{9}$ & $2.00(0)$ & $2.00(0)$ & $0.11(+\alpha)$ & 249590 & 10476 \\
$\mathbf{1 0}$ & $3.00(+1)$ & $3.00(+1)$ & $0.09(+1)$ & 267285 & 11995 \\
$\mathbf{1 1}$ & $2.00(0)$ & $0.32(-\alpha)$ & $0.06(0)$ & 255440 & 11825 \\
$\mathbf{1 2}$ & $2.00(0)$ & $2.00(0)$ & $0.06(0)$ & 231045 & 9537 \\
$\mathbf{1 3}$ & $3.68(+\alpha)$ & $2.00(0)$ & $0.06(0)$ & 269895 & 11548 \\
$\mathbf{1 4}$ & $1.00(-1)$ & $1.00(-1)$ & $0.09(+1)$ & 250185 & 9797 \\
$\mathbf{1 5}$ & $1.00(-1)$ & $3.00(+1)$ & $0.03(-1)$ & 260245 & 10865 \\
$\mathbf{1 6}$ & $2.00(0)$ & $2.00(0)$ & $0.06(0)$ & 231915 & 9512 \\
$\mathbf{1 7}$ & $3.00(+1)$ & $1.00(-1)$ & $0.09(+1)$ & 266475 & 11067 \\
$\mathbf{1 8}$ & $2.00(0)$ & $2.00(0)$ & $0.06(0)$ & 231605 & 9543 \\
$\mathbf{1 9}$ & $3.00(+1)$ & $3.00(+1)$ & $0.03(-1)$ & 268385 & 11646 \\
$\mathbf{2 0}$ & $2.00(0)$ & $2.00(0)$ & $0.01(-\alpha)$ & 241585 & 10623 \\
\hline
\end{tabular}

Table 2 presents the data resulting from investigation of the effect of three independent variables, $\mathrm{N}_{\mathrm{U}}\left(\mathrm{X}_{1}\right), \mathrm{N}_{2}\left(\mathrm{X}_{2}\right)$ and $\lambda\left(\mathrm{X}_{3}\right)$ on the two responses ISE $\left(\mathrm{R}_{1}\right)$ and $\operatorname{IAE}\left(\mathrm{R}_{2}\right)$. The data in Table 2 were run through RSM to construct an empirical models for the representation of ISE and IAE in terms of $\mathrm{N}_{\mathrm{U}}, \mathrm{N}_{2}$ and $\lambda$ tuning parameters of GPC. Based on regression analysis at $95 \%$ of confidence interval, the lack of fit error and p-values of parameter estimations were found to be significant. This indicates that a model except linear would better fit the data. The quadratic models were used to fit the observed data by least squares analysis and the following empirical models were obtained for ISE and IAE as Eq (9) and Eq (10), respectively.

$\mathbf{I S E}=+3.36485 \mathrm{E}+5-50309.71478 *\left[\mathbf{N}_{\mathbf{U}}\right]-47693.29590 *\left[\mathbf{N}_{2}\right]-1.05636 \mathrm{E}+6 *[\lambda]$

$+748.12500 *\left[\mathbf{N}_{\mathbf{U}} * \mathbf{N}_{2}\right]+92854.16667 *\left[\mathbf{N}_{\mathbf{U}} * \lambda\right]+35562.50000 *\left[\mathbf{N}_{2} * \lambda\right]$

$+11966.05280 *\left[\mathbf{N}_{U}{ }^{2}\right]+11327.00505 *\left[\mathbf{N}_{2}^{2}\right]+6.39052 \mathrm{E}+6 *\left[\lambda^{2}\right]$

$\mathbf{I A E}=+16561.75948-2790.00207 *\left[\mathbf{N}_{\mathbf{U}}\right]-2891.92883 *\left[\mathbf{N}_{2}\right]-60474.91688 *[\lambda]$

$+214.00000 *\left[\mathbf{N}_{\mathbf{U}} * \mathbf{N}_{2}\right]+2875.00000 *\left[\mathbf{N}_{\mathbf{U}} * \lambda\right]+2800.00000 *\left[\mathbf{N}_{2} * \lambda\right]$

$+622.25414 *\left[\mathbf{N}_{\mathbf{U}}{ }^{2}\right]+625.43612 *\left[\mathbf{N}_{2}{ }^{2}\right]+4.03247 \mathrm{E}+5 *\left[\lambda^{2}\right]$ 


\subsection{Analysis of Variance (ANOVA) for ISE and IAE}

In order to ensure the statistical significance of the quadratic model employed for explaining the experimental data at a 95\% confidence level, the model was tested by analysis of variance (ANOVA) results. The ANOVA of regression parameters of the RSM quadratic model for the tuning parameters of GPC are listed in Table 3 and Table 4 for ISE and IAE values, respectively. On the basis of the experimental values, statistical testing was carried out using Fisher's test for ANOVA.

From Table 3 and Table 4 it were observed that the regression was statistically significant at an F-value of 20.21 for ISE and 193.87 for IAE values with a very low probability value ( $\mathrm{P}$ model $<0.0001)$ on the wireless temperature control. Therefore, in the quadratic model that describes our process, an adequate precision of 12.31 for ISE and 159.34 for IAE values, indicates a satisfactory signal for the process. The statistical significance of the second-order equation revealed that the regression is statistically significant $(\mathrm{P}<0.0001)$; however, the lack of fit is not statistically significant at $99 \%$ confidence level. The results indicate that the response equation proved to be suitable for the CCD experiments. The fit of the model was controlled by the coefficient of determination $\mathrm{R}^{2}$. Based on the ANOVA results, the model reports high $\mathrm{R}^{2}$ values of $94.79 \%$ for ISE and $99.43 \%$ for IAE were found. Also, an acceptable agreement with the adjusted determination coefficient is necessary. In this study, the adjusted $\mathrm{R}^{2}$ values of $90.10 \%$ for ISE and $98.92 \%$ for IAE were found. The values of $\mathrm{R}^{2}$ are advocates a high correlation between the observed values and the predicted values. This indicates that the regression model provides a good explanation of the relationship between the three independent variables and the two responses.

The normal percentage probability and studentized residual plots are shown in Figure 3 and Figure 4 for ISE and IAE, respectively. As the points on the plot flow a straight lines, it can be concluded that the residuals are normally distributed and data transformation is not required. Therefore, it concluded that the prediction of the experimental data by developed quadratic models for the wireless GPC results are quite satisfactory. Therefore, the regression models can be used to predict the ISE and IAE values from the experimental conditions.

Table 3. ANOVA Results for ISE

\begin{tabular}{|c|c|c|c|c|c|}
\hline Source & $\begin{array}{l}\text { Sum of } \\
\text { Squares }\end{array}$ & df & $\begin{array}{c}\text { Mean } \\
\text { Square }\end{array}$ & $\begin{array}{c}\mathbf{F} \\
\text { Value }\end{array}$ & $\begin{array}{c}\mathbf{p} \\
\text { Value }\end{array}$ \\
\hline Model & $4.16 \mathrm{E}+12$ & 9 & $4.62 \mathrm{E}+11$ & 20.21 & $<0.0001$ \\
\hline$A-N_{U}$ & $2.92 E+11$ & 1 & $2.92 \mathrm{E}+11$ & 12.76 & 0.0051 \\
\hline B- $\mathrm{N}_{2}$ & $2.12 \mathrm{E}+10$ & 1 & $2.12 \mathrm{E}+10$ & 0.93 & 0.3587 \\
\hline$C-\lambda$ & $1.31 E+10$ & 1 & $1.31 \mathrm{E}+10$ & 0.57 & 0.4662 \\
\hline$A B$ & $4.48 E+09$ & 1 & $4.48 \mathrm{E}+09$ & 0.20 & 0.6675 \\
\hline$A C$ & $6.21 E+10$ & 1 & $6.21 \mathrm{E}+10$ & 2.72 & 0.1304 \\
\hline$B C$ & $9.11 \mathrm{E}+09$ & 1 & $9.11 \mathrm{E}+09$ & 0.40 & 0.5421 \\
\hline$A^{2}$ & $2.06 \mathrm{E}+12$ & 1 & $2.06 \mathrm{E}+12$ & 90.28 & $<0.0001$ \\
\hline$B^{2}$ & $1.85 E+12$ & 1 & $1.85 \mathrm{E}+12$ & 80.90 & $<0.0001$ \\
\hline$C^{2}$ & $4.77 \mathrm{E}+11$ & 1 & $4.77 \mathrm{E}+11$ & 20.86 & 0.0010 \\
\hline Residual & $2.29 E+11$ & 10 & $2.29 \mathrm{E}+10$ & & \\
\hline Lack of Fit & $2.27 E+11$ & 5 & $4.54 \mathrm{E}+10$ & 158.44 & $<0.0001$ \\
\hline Pure Error & $1.43 E+09$ & 5 & $2.87 E+08$ & & \\
\hline
\end{tabular}


Table 4. ANOVA Results for IAE

\begin{tabular}{|cccccc|}
\hline Source & $\begin{array}{c}\text { Sum of } \\
\text { Squares }\end{array}$ & $\mathbf{d f}$ & $\begin{array}{c}\text { Mean } \\
\text { Square }\end{array}$ & $\begin{array}{c}\mathbf{F} \\
\text { Value }\end{array}$ & $\begin{array}{c}\mathbf{p} \\
\text { Value }\end{array}$ \\
\hline Model & $1,34 \mathrm{E}+10$ & 9 & $1,49 \mathrm{E}+09$ & 193.87 & $<0.0001$ \\
$\mathrm{~A}-\mathrm{N}_{\mathrm{U}}$ & $1,23 \mathrm{E}+09$ & 1 & $1,23 \mathrm{E}+09$ & 159.34 & $<0.0001$ \\
$\mathrm{~B}-\mathrm{N}_{2}$ & $5,79 \mathrm{E}+08$ & 1 & $5,79 \mathrm{E}+08$ & 75.24 & $<0.0001$ \\
$\mathrm{C}-\lambda$ & 6643.96 & 1 & 6643.96 & 0.86 & 0.3745 \\
$\mathrm{AB}$ & $3,66 \mathrm{E}+08$ & 1 & $3,66 \mathrm{E}+08$ & 47.65 & $<0.0001$ \\
$\mathrm{AC}$ & 59512.50 & 1 & 59512.50 & 7.74 & 0.0194 \\
$\mathrm{BC}$ & 56448.00 & 1 & 56448.00 & 7.34 & 0.0220 \\
$\mathrm{~A}^{2}$ & $5,58 \mathrm{E}+09$ & 1 & $5,58 \mathrm{E}+09$ & 725.74 & $<0.0001$ \\
$\mathrm{~B}^{2}$ & $5,64 \mathrm{E}+09$ & 1 & $5,64 \mathrm{E}+09$ & 733.18 & $<0.0001$ \\
$\mathrm{C}^{2}$ & $1,90 \mathrm{E}+09$ & 1 & $1,90 \mathrm{E}+09$ & 246.87 & $<0.0001$ \\
Residual & 76887.47 & 10 & 7688.75 & & \\
Lack of Fit & 74884.14 & 5 & 14976.83 & 37.38 & 0.0006 \\
Pure Error & 2003.33 & 5 & 400.67 & & \\
\hline
\end{tabular}

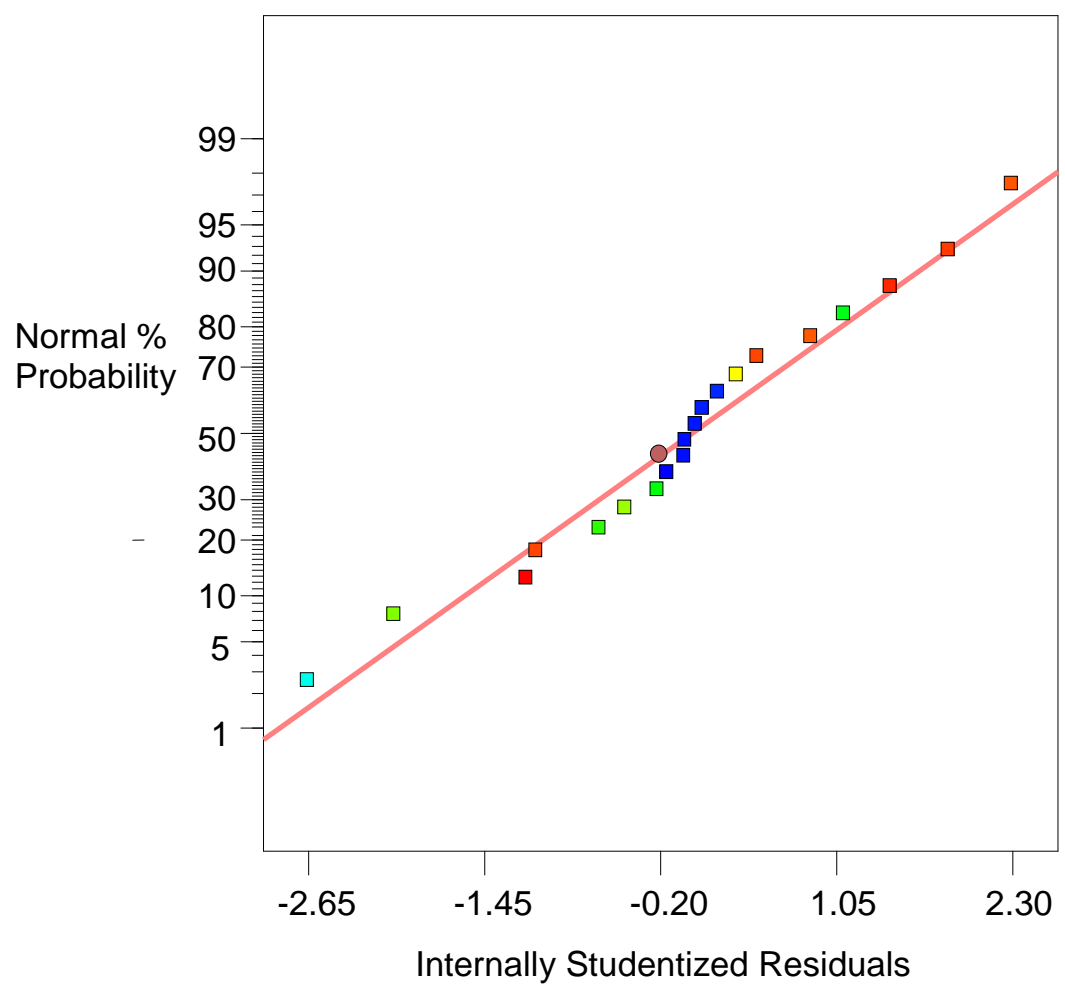

Figure 3. Normal Probability Plot of the Studentized Residual for ISE 


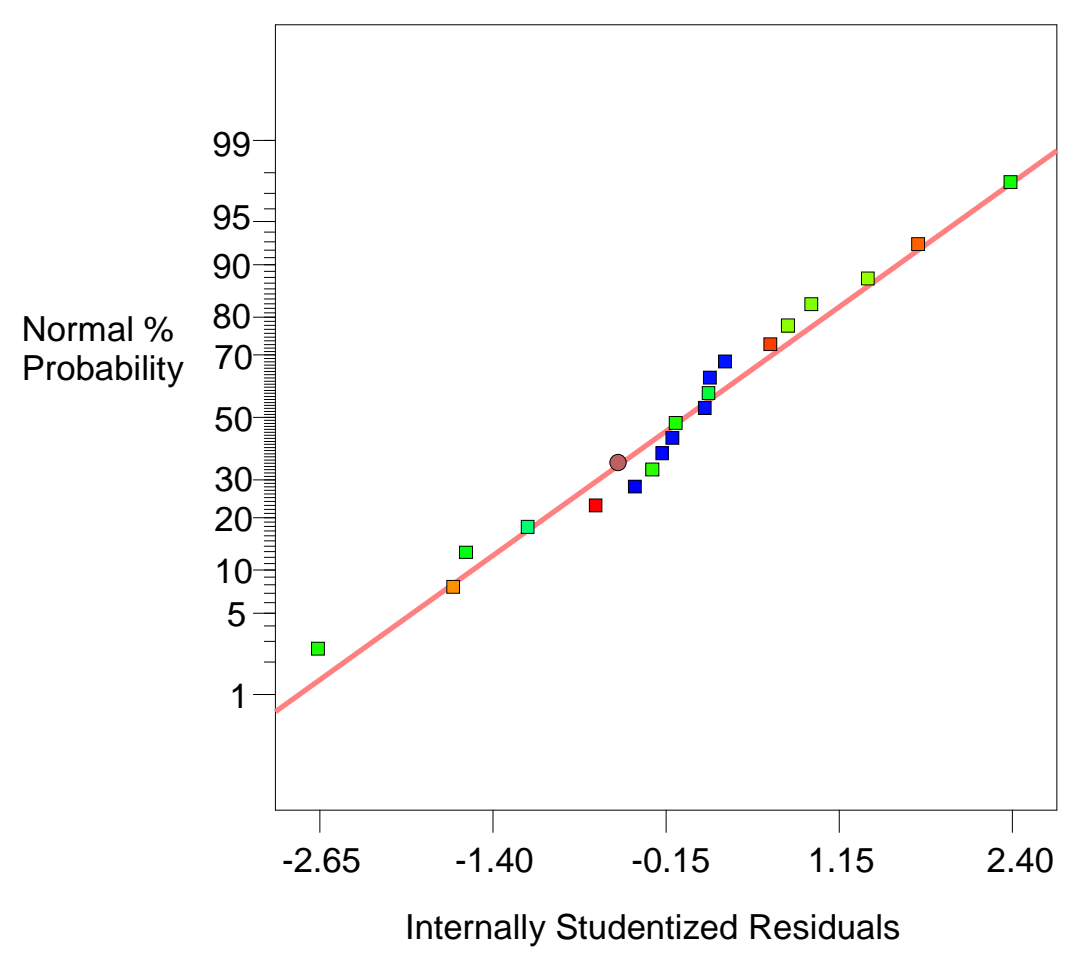

Figure 4. Normal Probability Plot of the Studentized Residual for IAE

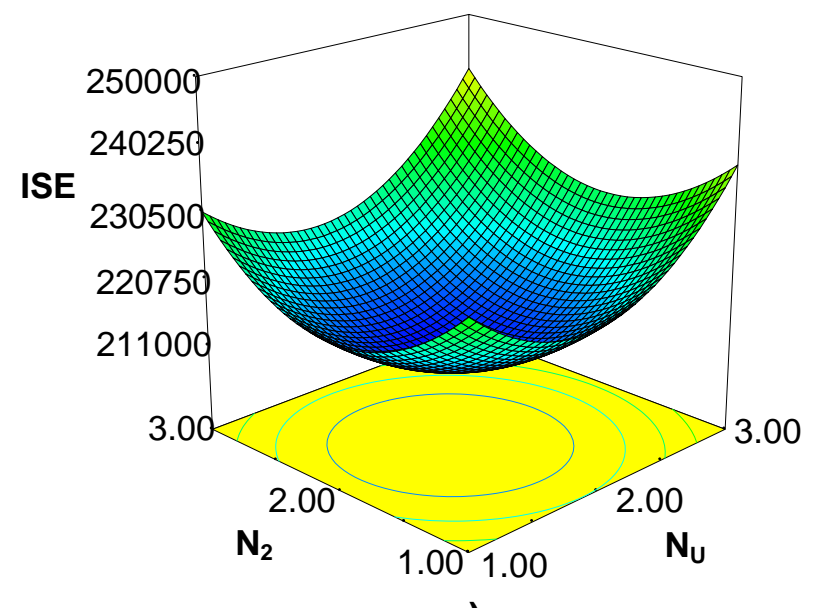

a) 


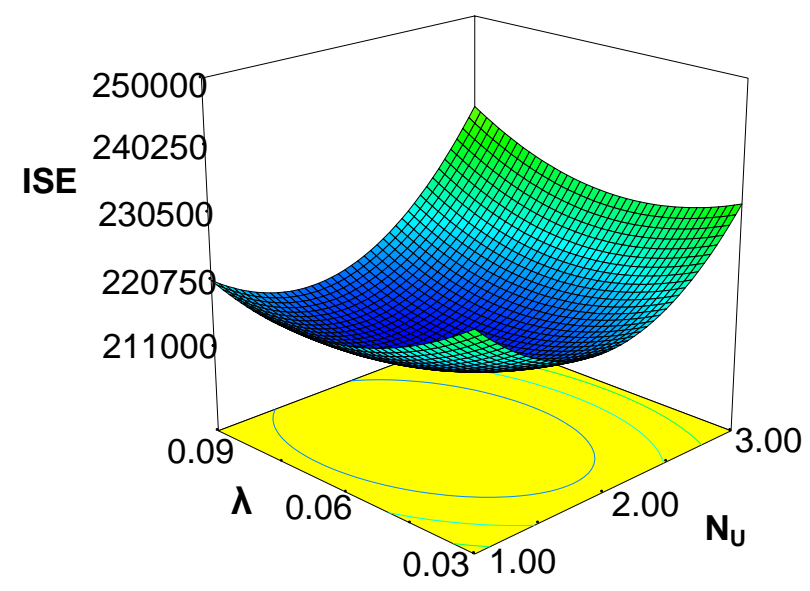

b)

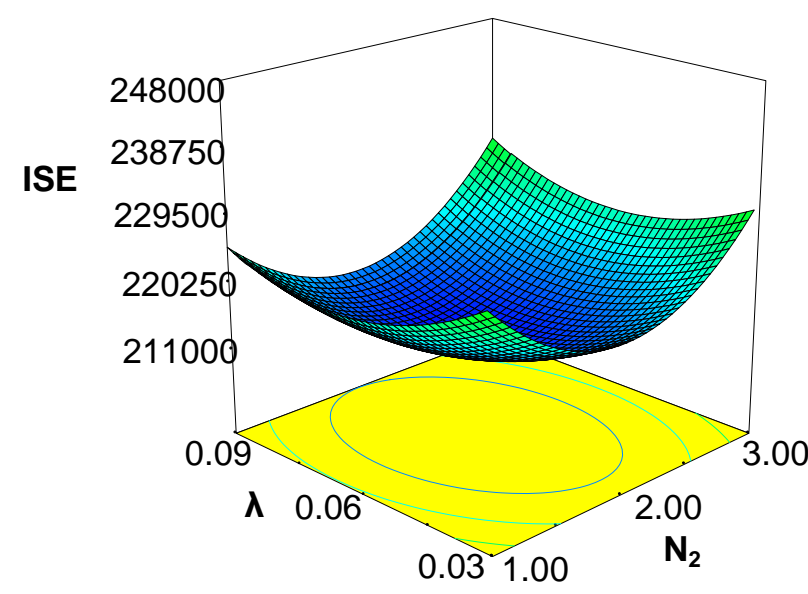

c)

Figure 5. Three-dimensional (3D) Response Surface Curves for the Simultaneous Effects of $N_{U}\left(X_{1}\right), N_{2}\left(X_{2}\right)$ and $\lambda\left(X_{3}\right)$ on the ISE

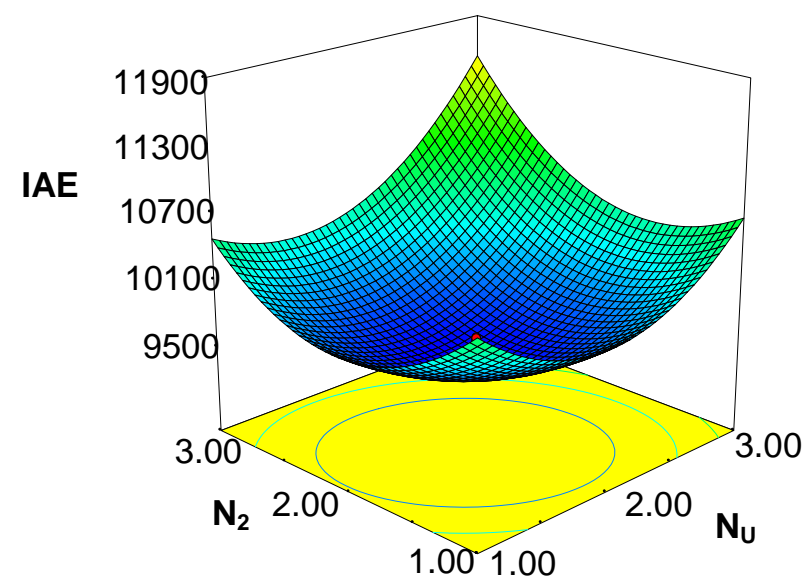

a) 


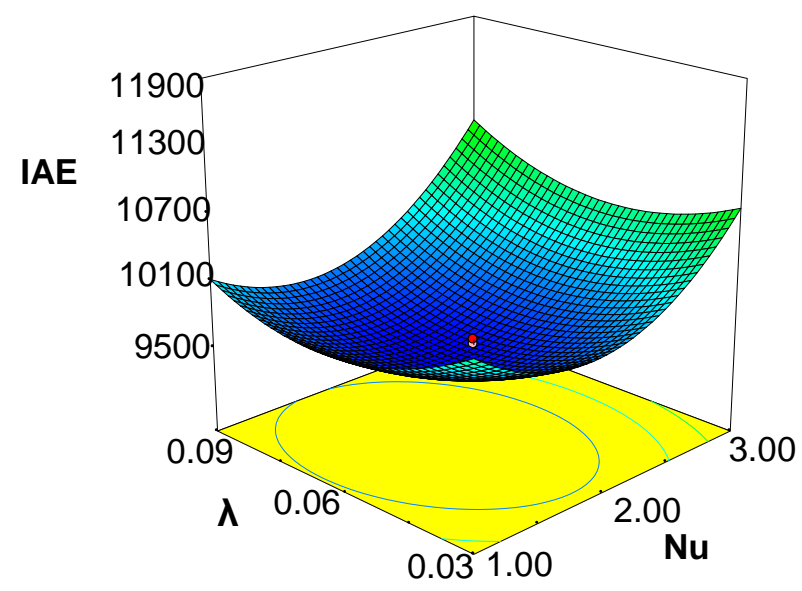

b)

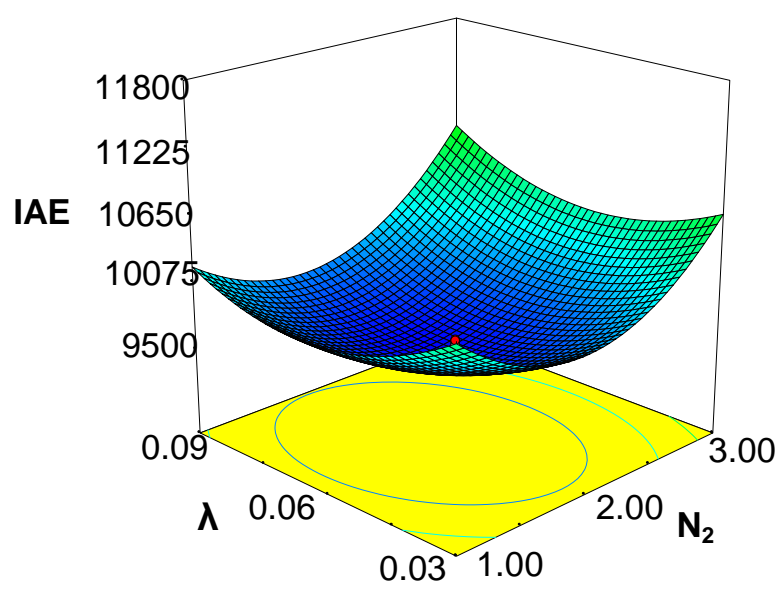

c)

\section{Figure 6. Three-dimensional (3D) Response Surface Curves for the Simultaneous Effects of $N_{U}\left(X_{1}\right), N_{2}\left(X_{2}\right)$ and $\lambda\left(X_{3}\right)$ on the IAE}

Figure 5 and Figure 6 describes the response surface profiles for the calculated ISE and IAE values of wireless temperature control with GPC tuning parameters, respectively. The curvatures nature of 3-dimensional surfaces showed that there is significant and moderate interactions among the variables considered for the ISE and IAE values. Figure $5(\mathrm{a}, \mathrm{b}, \mathrm{c})$ indicates the mutual interaction of ISE with $\mathrm{N}_{\mathrm{U}}, \mathrm{N}_{2}$, ISE with $\mathrm{N}_{\mathrm{U}}, \lambda$, and ISE with $\mathrm{N}_{2}, \lambda$ and Figure $6(\mathrm{a}, \mathrm{b}, \mathrm{c})$ indicates the mutual interaction of IAE with $\mathrm{N}_{\mathrm{U}}, \mathrm{N}_{2}$, IAE with $\mathrm{N}_{\mathrm{U}}, \lambda$, and IAE with $\mathrm{N}_{2}, \lambda$ respectively.

The plot for the interaction between $\mathrm{N}_{\mathrm{U}}, \mathrm{N}_{2}$ and $\lambda$ (Fig. 5a,b,c) shows that increasing two independent variables above and below the center points increases the ISE values. Similarly in Fig. 6 (a, b, c) two independent variables above and below the center points increases the IAE values. Based on Figure 5 and Figure 6 optimum points of GPC tuning parameters close to center points of experimental conditions.

The optimum magnitudes of the most significant parameters to minimize the ISE and IAE values for experimental wireless temperature control with GPC tuning parameters were evaluated by application of Equation (8). The $x s, b$ and $B$ matrices in Equation (8) were arranged by Equation (9) and Equation (10), for ISE and IAE respectively, which includes the effects of the tested parameters. $x s, b$ and $B$ matrices were formed as follows [18]: 


$$
\begin{aligned}
& x_{s}=\left[\begin{array}{l}
\mathrm{X}_{1} \\
\mathrm{X}_{2} \\
\mathrm{X}_{3}
\end{array}\right] \quad, \quad b=\left[\begin{array}{l}
-50309.71478 \\
-47693.29590 \\
-1056360.000
\end{array}\right] \\
& B=\left\{\begin{array}{ccc}
+11966.05280 & +748.12500 / 2 & +92854.16667 / 2 \\
+748.12500 / 2 & +11327.00505 & +35562.50000 / 2 \\
+92854.16667 / 2 & +35562.50000 / 2 & +6390520.0000
\end{array}\right]
\end{aligned}
$$

Optimum values of $\mathrm{N}_{\mathrm{U}}\left(\mathrm{X}_{1}\right), \mathrm{N}_{2}\left(\mathrm{X}_{2}\right)$ and $\lambda\left(\mathrm{X}_{3}\right)$ for minimize the ISE were calculated to be $1.7922,1.9453$ and 0.0642 , respectively.

$$
\begin{aligned}
& x_{s}=\left[\begin{array}{l}
\mathrm{X}_{1} \\
\mathrm{x}_{2} \\
\mathrm{x}_{3}
\end{array}\right] \quad, \quad b=\left[\begin{array}{r}
-2790.00207 \\
-2891.92883 \\
-60474.91688
\end{array}\right] \\
& B=\left[\begin{array}{ccc}
+622.25414 & +214.00000 / 2 & +2875.00000 / 2 \\
+214.00000 / 2 & +625.43612 & +2800.00000 / 2 \\
+2875.00000 / 2 & +2800.00000 / 2 & +4032470.0000
\end{array}\right]
\end{aligned}
$$

Optimum values of $\mathrm{N}_{\mathrm{U}}\left(\mathrm{X}_{1}\right), \mathrm{N}_{2}\left(\mathrm{X}_{2}\right)$ and $\lambda\left(\mathrm{X}_{3}\right)$ for minimize the IAE were calculated to be $1.8880,1.9752$ and 0.0612 , respectively.

\section{Conclusions}

A GPC algorithm was utilized to a process simulator for experimental wireless temperature control. The experimental GPC results and efficiency of the GPC algorithm determined with different values of $\mathrm{N}_{\mathrm{U}}, \mathrm{N}_{2}$ and $\lambda$ tuning parameters are compared by calculated ISE, IAE values. RSM was successfully applied to GPC results which determined the optimum tuning parameters for minimum ISE and IAE values. Quadratic models, developed in terms of $\mathrm{N}_{\mathrm{U}}, \mathrm{N}_{2}$ and $\lambda$ tuning parameters to represents the calculated ISE and IAE and corresponding coefficient of variables were estimated by the application of Design Expert 7.0.0 program trial version. Based on statistic analysis, optimum GPC tuning parameters of $\mathrm{N}_{\mathrm{U}}\left(\mathrm{X}_{1}\right), \mathrm{N}_{2}\left(\mathrm{X}_{2}\right)$ and $\lambda\left(\mathrm{X}_{3}\right)$ for minimize the ISE were determined to be $1.7922,1.9453$ and 0.0642 and for minimize the IAE were determined to be 1.8880, 1.9752 and 0.0612 , respectively. Calculated optimum points of GPC tuning parameters are close to based on ISE and IAE results. The data evaluated from the quadratic model were good agreement with those measured experimentally. The wireless generalized predictive temperature control is successfully applied to the process simulator and wireless process control technique is proposed for various application areas because of minimization of cabling costs, smaller engineering devices, required low energy, low power consumption, flexibility, scalability and assembly times, the ease of system extensions and changes and the possibility to apply sensors to mobile devices and device parts.

\section{Acknowledgements}

The authors would like to thanks the Ankara University, Research Fund for providing financial support this research; Ankara, Turkey 


\section{References}

[1] D.W. Clarke, C. Mohtadi, and P.S. Tuffs, "Generalized Predictive Control, Part I. The Basic Algoritm", Automatica, vol. 23, no. 2, (1987), pp. 137-148.

[2] D.W. Clarke, C. Mohtadi, and P.S. Tuffs, "Generalized Predictive Control, Part II. Extensions and Interpretations", Automatica, vol. 23, no. 2, (1987), pp. 149-160.

[3] D.W. Clarke and C. Mohtadi, "Properties of Generalized Predictive Control", Automatica vol. 25, no. 6, (1989), pp. 869-876.

[4] H. Demircioglu, E. Karasu, "Generalized Predictive Control. A Practical Application and Comparison of Discrete and Continuous Time Versions", IEEE Control Syst. Mag., vol. 20, no. 5, (2000), pp. 36-47.

[5] S. Karacan, H. Hapoğlu and M. Alpbaz, "Application of Optimal Adaptive Generalized Predictive Control to A Packed Distillation Column", Chemical Engineering Journal, vol. 84, no. 3, pp. 389-396, (2001).

[6] G. Özkan, H. Hapoğlu, M. Alpbaz, "Non-Linear Generalized Predictive Control of A Jacketed Well Mixed Tank As Applied To A Batch Process-A Polymerisation Reaction", Applied Thermal Engineering, vol. 26, no. 7, (2006), pp. 720-726.

[7] A. Majdoul, M. Haloua and H. Youlal, "Generalized Predictive Control of An Industrial Calcination Reactor", Advanced Control of Chemical Processes, IFAC Symposium, (1991), October 14-16; Toulouse, France.

[8] A. Altınten, "Generalized Predictive Control Applied to A pH Neutralization Process", Computers and Chemical Engineering, vol. 31, no. 10, (2007), pp. 1199-1204.

[9] N. Bursal1, B. Akay, S. Ertunc, H. Hapoglu, M, Alpbaz, "New Tuning Method For Generalized Predictive Control of The Production of S. Cerevisiae", Trans IChemE, vol. 79, (2001), pp. 27-34.

[10] C. Diaz, P. Dieu, C. Feuillerat, P. Lelong, "Salome, M., Adaptive predictive control of dissolved oxygen concentration in a laboratory-scale bioreactor", Journal of Biotechnology, vol. 43, (1995), pp. 21-32.

[11] J. Zhang, Y. Zhou, Y. Li, G. Hou, F. Fang, "Generalized predictive control applied in waste heat recovery power plants", Applied Energy, vol. 102, (2013), pp. 320-326.

[12] M. Suichies, D. Leroux, C. Decher, A. Trusiak, “An Implementation of Generalized Predictive Control In A Flotation Plant", Control Engineering Practice, vol. 8, (2000), pp. 319-325.

[13] A. R. McIntosh, S. L. Shah and D. G. Fisher, "Analysis and Tuning of Adaptive Generalized Predictive Control", Canadian Journal of Chemical Engineering, vol. 69, (1991), pp. 97-110.

[14] A. Aldemir, H. Hapoğlu, M. Alpbaz, "Application of MATLAB/Simulink Program for Wireless Generalized Predictive Control”, International Journal of Engineering and Innovative Technology (IJEIT), vol. 3, no. 12, (2014), pp. 19-22.

[15] B.W. Bequette, "Process Control: Modeling, Design and Simulation", Prentice Hall, (2003).

[16] D. Seborg, D. Mellichamp, T. Edgar, F. Doyle, Process Dynamics and Control, (2011).

[17] P3005 Process Control Simulator hand book.

[18] R. H. Myers, D. C. Montgomery, "Response Surface Methodology", John Wiley and Sons, (2000). 
International Journal of Control and Automation Vol. 8, No. 2 (2015) 